\title{
Faculty Members' Experiences of Cyberbullying by Students at One Canadian University: Impact and Recommendations
}

\author{
Lida Marie Blizard ${ }^{1}$ \\ ${ }^{1}$ Faculty of Health, Kwantlen Polytechnic University, Surrey, British Columbia, Canada \\ Correspondence: Lida Marie Blizard, Ed.D., Faculty of Health, Kwantlen Polytechnic University, 12666-72 Ave. \\ Surrey, B.C., V3W 2M8, Canada.
}

Received: December 22, 2015

Accepted: January 11, 2016

Online Published: January 26, 2016

doi:10.5430/irhe.v1n1p107

URL: http://dx.doi.org/10.5430/irhe.v1n1p107

\begin{abstract}
This two-phase mixed methods study adopted online survey and individual interview questions to explore faculty members' experiences of cyberbullying by students at one Canadian university. Foucault's (1994) power relations theory was used to explore the power dynamic that can exist in the student-faculty relationship. The study found that cyberbullied faculty members were commonly female, over 40 years of age, English-speaking Canadian citizens, and held fulltime rank. Cyberbullying occurred namely via email, end-of-term faculty evaluation sites, and public polling sites (e.g. Ratemyprofessor.com), while students' dissatisfaction with grades was the most common precursor. Consistent with prior bullying and cyberbullying literature, this study also found that cyberbullied faculty members experienced detrimental effects, persisting from a few days to more than one year. The under-researched focus of this study advances existing workplace bullying and cyberbullying research by illuminating both the harmful implications of student-to-faculty cyberbullying, and the support measures deemed necessary by targeted individuals.
\end{abstract}

Keywords: cyberbullying, university, faculty, students, impact, recommendations

\section{Introduction}

There is growing concern that the relatively safe environment of higher education has shifted in the occurrence of aggression, as more studies of academic workplace bullying and cyberbullying emerge (Clark, Faan, Werth, \& Ahten, 2012; Keashly \& Neuman, 2013; Lampman, Phelps, Bancroft, \& Beneke, 2009; Nicoletti \& Spencer-Thomas, 2010; Schenk \& Fremouw, 2012). For faculty members, the classroom (whether in-person or virtual) constitutes the workplace where faculty are held to uphold a safe, engaging learning environment and mitigate tensions that can arise in the process. Further, with the advances in communication technology, student to faculty exchanges now transcend beyond the confines of the traditional face-to-face classroom to online platforms such as chat rooms, email, and blogs (Belsey, 2008; Campbell, 2005; Shariff, 2008). While such modalities pose lucrative opportunities for positive faculty-student engagement and enriched learning, studies report that electronic media has also served as a convenient platform for bullying--a phenomenon coined as cyber-bullying (Eskey, Taylor, \& Eskey, 2014; Patchin \& Hinduja, 2006; Shariff, 2008; Smith, et al., 2008; Ybarra \& Mitchell, 2004; Zalaquett \& Chatters, 2014). Notably, student-faculty tensions are bound to occur, given the decisions that faculty members must make and the implications this can have on students' academic outcomes. Although faculty members may endeavor to resolve issues directly with the student in the form of a face-to-face discussion, students may opt for the more convenient ease of access and anonymity afforded by online platforms (e.g., end of term faculty evaluations, Facebook, Ratemyprofessors.com) to voice their concerns. Within their leadership role, there is an inherent expectation that faculty members draw upon institutional policy and procedures, evidence-based practices, and effective conflict resolution strategies to manage student discourse, yet may be challenged to do so in the absence of appropriate resources.

\subsection{Cyberbullying Literature}

Drawing from prior cyberbullying literature (Beale \& Hall, 2007; Brown, Jackson, \& Cassidy, 2006; Li, 2007; Patchin \& Hinduja, 2006, 2011; Shariff, 2008; Smith, 2012) throughout this study, cyberbullying refers to aggressive, intimidating, derogatory, defamatory, or bullying messages sent to or about a faculty member by a student(s) via online media (e.g., cellular phone, email, and polling websites such as Ratemyprofessor.com[RMP]). While definitions of cyberbullying vary across the literature, it is commonly described as unwanted behavior that is harmful 
to targeted individuals, and repetitive (Faucher, Cassidy, \& Jackson, 2015). While there is debate in the cyberbullying literature as to whether a single act of online aggression constitutes cyberbullying (Belsey, 2008; Hinduja \& Patchin, 2008; Slonje \& Smith, 2008; Spears, Slee, Owens, \& Johnson, 2009), this study considers that one act of online aggression or defamation towards a faculty member constitutes cyberbullying, given the permanence and the extent to which one message can be distributed to and viewed by multiple parties, as well as the negative effects endured by the target. Putting this into the student-faculty member context, one defamatory comment posted by a student on and end of term faculty evaluation site (potentially accessible to administrators), or to online public polling sites (e.g., RMP posts designed to rank faculty performance, likability, and attractiveness) can be viewed repeatedly by single or multiple audiences, including the target. Further, given the multiplicity and permanence of such postings, it is plausible that a single cyberbullying message can flourish, and repeatedly inflict harm on the targeted individual. For instance, Daniloff (2009) reported the account of a faculty member who, after confronting a student with plagiarism, endured hostile email messages that escalated into a two-year plague of defamatory comments on Ratemyprofessors.com., the implications of which left the faculty member feeling very stressed. As well, the posting is the first thing that surfaces upon Google search of the faculty member's name.

Within the academic realm, online aggression (namely student peer-to-peer) has been researched more extensively across the K-12 sector. As research advances, more studies exploring bullying, harassment, and cyberbullying within the post-secondary sector have begun to emerge and expose the nature, scope and complexity of this issue. While post-secondary education may have once been perceived as a relatively safe haven for faculty and students alike, the cyberbullying literature presents some formidable findings that challenge such assumptions. First, numerous studies across the K-12 and post-secondary sector report that cyberbullying can have detrimental effects on targeted individuals (Cassidy, Faucher, \& Jackson, 2013; Clark et al., 2012; Crosslin \& Golman, 2014; Finn, 2004; Hinduja \& Patchin, 2010; Jones \& Scott, 2012; Li, 2007). Second, there is agreement among scholars that bullying within the academic environment can negatively affect both the teaching a learning process (Glover, Gough, Johnson, \& Cartwright, 2000), and students' academic performance (Strøm, Thoresen, Wentzel-Larsen, \& Dyb, 2013).

\subsection{Cyberbullying in Post-secondary Education}

In terms of workplace safety for faculty, although research focused on post-secondary workplace bullying is marginal (Keashly \& Neuman, 2008; Keashly \& Neuman, 2010; Lampman et al., 2009; Lewis, 2004; McKay, Arnold, Fratzl, \& Thomas, 2008; Simpson \& Cohen, 2004), some studies report that approximately $18 \%$ to $32 \%$ of post-secondary faculty members have experienced bullying (Hoel \& Cooper, 2000; Keashly \& Neuman, 2010; McKay et al., 2008). Further, while studies exploring cyberbullying towards faculty members have begun to emerge (Beran \& Li, 2007; Clark et al., 2012; Lester, 2013; Minor, Smith, \& Brashen, 2013; Nardone, 2010; Wildermuth \& Davis, 2012), few studies have focused on student-to-faculty targeted cyberbullying (Eskey, Taylor, \& Eskey, 2014; Minor et al., 2013). Notably, prior to cyberbullying specific research, reports of online aggression towards faculty members (e.g. threatening email messages) surfaced in earlier studies of student aggression and incivility (Dickerson, 2005; Lampman et al., 2009; Luparell, 2004, 2007), suggesting that student-to-faculty aggression via online media existed prior to being coined as cyberbullying. For instance, Lampman et al. (2009) found that approximately $50 \%$ of faculty members encountered hostile comments from students via end of term faculty evaluations, and approximately $30 \%$ received threatening email messages. Based on the aforementioned findings, we know that within their teaching role, faculty members can be exposed to harmful student behaviors ranging from incivility to aggression, or worse--violence.

Preliminary studies of cyberbullying within the post-secondary sector focused primarily on the student population (Francisco, Simão, Ferreira, \& das Dores Martins, 2015; Schenk \& Fremouw, 2012; Schenk, Fremouw, \& Keelan, 2013; Smith \& Yoon, 2013; Ybarra, Diener-West, \& Leaf, 2007; Zalaquett \& Chatters, 2014), reporting prevalence rates that have ranged between $10 \%$ to 20\% (Finn, 2004; Smith \& Yoon, 2013; Walker, Sockman, \& Koehn, 2011; Zalaquett \& Chatters, 2014), as well as $25 \%$ in a study of students at four universities (Faucher, Jackson, \& Cassidy, 2014 ), and higher at $28.7 \%$ (Hinduja \& Patchin, 2010). These findings bear similarity to K-12 prevalence rates $(20 \%$ to $40 \%$ ) that were reported by Tokunaga (2010) in a synthesis of twenty-five K-12 studies. While student-to-faculty targeted cyberbullying remains under-researched, some studies report relatively high prevalence rates ranging between $12 \%$ (Faucher et al., 2014), and $17 \%$ to $45 \%$ reported in studies that focused on cyberbullying of faculty members who taught online courses (Clark et al., 2012; Eskey et al., 2014b; Minor et al., 2013; Smith, 2007; Vance, 2010). The similarities in prevalence rates between K-12 and higher education sectors are intriguing and challenge the suggestion by some researchers (Cassidy et al., 2009; Patchin \& Hinduja, 2012) that cyberbullying diminishes as adolescent students mature, graduate, and draw upon more effective problem-solving skills as adults in higher education. In addition to knowing that cyberbullying extends from K-12 to post-secondary, there is evidence to 
suggest that campus constituents are concerned about this phenomenon. For instance Molluzzo and Lamber's (2014) study found that approximately one third of faculty members reported that cyberbullying was a serious issue for them, yet with limited literature pertaining to cyberbullying of faculty members, it is difficult to discern the scope and breadth of the problem.

\subsection{Impact of Cyberbullying}

There is consistency across the workplace, $\mathrm{K}-12$, and post-secondary bullying literature that both face-to-face bullying and cyberbullying can be physically and emotionally harmful to targeted individuals (Beran \& Lupart, 2009; Beran, Rinaldi, Bickham, \& Rich, 2012; Cassidy, Brown, \& Jackson, 2012; Eskey et al., 2014b; Na, Dancy, \& Park, 2015; Patchin \& Hinduja, 2010; Schenk \& Fremouw, 2012b; Shariff, 2008; Smith et al., 2008). Further, studies of faculty-targeted incivility (Lampman, 2012; Lampman et al., 2009; Luparell, 2004), and cyberbullying towards faculty members (Clark et al., 2012; Eskey et al., 2014b; Faucher et al., 2014; Minor et al., 2013) report harmful effects on targeted individuals. The literature also informs that targeted individuals tend to avoid reporting bullying for fear of retaliation, further repercussions, or being labeled by others in a negative light (Agatson, Kowalski, \& Limber, 2012: Cassidy et al., 2011; Smith \& Slonje, 2010; Yilmaz, 2011). It is important to consider that the prevalence rates may be under-represented as well.

Given the impact that cyberbullying has had on targeted individuals across the K-12 and post-secondary sector, it is therefore plausible that faculty members who encounter cyberbullying by students may experience detrimental physical and emotional effects. The importance of this issue is paramount, given the degree of harm that may be incurred by targeted faculty members, and the context within which it occurs--the classroom which serves as their workplace environment. Keeping with this view, cyberbullying of faculty members by students constitutes a form of workplace violence.

\subsection{Purpose}

While cyberbullying of faculty members has received some public attention (e.g., Prigden vs. University of Calgary), and media exposure of recent K-12 cyberbullying tragedies has spiked international attention (e.g., Amanda Todd), we don't know the extent to which student-to-faculty targeted cyberbullying occurs, the impact on victims, nor the support needed by faculty members to effectively manage cyberbullying incidents. Despite the expansive amount of $\mathrm{K}-12$ cyberbullying research exploring prevalence, impact, and recommendations for institutional policy, at the time of this study, the limited amount of post-secondary cyberbullying literature challenged faculty members' ability to manage cyberbullying effectively within the context of higher education. Of further consideration, in the immediacy of being cyberbullied, individual's actions may vary depending on their knowledge of cyberbullying, their confidence and competence to respond, the degree to which they have been affected, and if negatively affected, their resilience in coping with stressors thereafter. This begs the question as to how targeted faculty members maintain a sense of safety on campus or manage the tensions that are bound to arise in the student-faculty relationship in the aftermath of cyberbullying. After all, in the absence of therapeutic support measures to draw upon, it is plausible that cyberbullied faculty members may return to their teaching role while processing unresolved distress--the implications of which cannot be disregarded.

The purpose of this research study was first, to understand faculty members' perceptions and impact of having harmful messages sent to them or about them via online media, and second to explore the support measures that they believed to be necessary to manage cyberbullying. In order to understand cyberbullied faculty members' experiences, we asked the following research questions:

1) How did faculty members who received at least one cyberbullying message from a student within the past 24 months perceive the experience?

2) What impact did targeted faculty members' most serious cyberbullying experiences have on them?

3) How did targeted faculty members respond to their most serious cyberbullying experience?

4) What support measures did cyberbullied faculty members need in order to effectively manage cyberbullying.

\subsection{Theoretical Frameworks}

Three of the more prominent theoretical constructs that have been used across the bullying literature to explain this phenomenon include power relations between aggressors and targets (Grigg, 2010; Kowalski, Limber, \& Agatston, 2012; Monks, Robinson, \& Worlidge, 2012; Vandebosch \& Van Cleemput, 2009; Walker, Sockman, \& Koehn, 2011); relational aggression (Cassidy, Jackson, \& Brown, 2009) and the victimization of targeted individuals 
(Cassidy et al., 2009; Dooley, Gradinger, Strohmeier, Cross, \& Spiel, 2010; Hinduja \& Patchin, 2007; Li, 2007; Monks et al., 2012; Ortega, Elipe, Mora-Merchán, Calmaestra, \& Vega, 2009; Smith, Mahdavi, Carvalho, \& Tippett, 2006; Smith, 2009; Smith et al., 2008; von Marées \& Petermann, 2012; Walker et al., 2011; Ybarra \& Mitchell, 2004). Faucher et al. (2014) propose that three theoretical lenses of relational aggression, affective and cognitive empathy deficits, as well as the power and control model are useful in advancing our understanding cyberbullying in higher education. Yet although this study is situated within the domains of "workplace bullying" and "cyberbullying", the focus is unique such that the aggressor-target trajectory is student-to-faculty (contra-hierarchal), versus peer-to-peer (non-hierarchal). The conceptual framework drew upon power theories given the prominence of power concepts that have surfaced in studies of student aggression, workplace bullying, and student misconduct (DeSouza, 2010; Einarsen, Hoel, Zapf, \& Cooper, 2003; Olweus, 1991; Rayner \& Keashly, 2005; Rodríguez-Muñoz, Moreno-Jiménez, Vergel, \& Hernández, 2010; Salin, 2003; Twale \& DeLuca, 2008).

Foucault's (1994) power relations theory was used to explore the power dynamic that can exists in the student-faculty relationship, in belief that student-to-faculty cyberbullying may serve as a means for students, frustrated by academic pressures and emboldened by their proficiency with electronic media, to shift a 'faculty-over-student' power imbalance. For instance, Foucault (1977) argues that power can be used to regulate the behavior of others, and while sovereign power was commonly exercised by kings to exert authority over subjects, disciplinary power was less forceful, yet more complex in the relational interplay in the day to day interactions between individuals. Even though such approaches could be repressive, disciplinary power served to be productive in meeting individual or collective needs, thereby fostering compliance and acceptance (Foucault, 1977). From this perspective, the institutional hierarchy and student-faculty relationship exemplify the disciplinary power that is held within post-secondary education such that the institutional policies and practices guide constituents' conduct, and while it may be perceived as repressive for students in terms of their ability to influence the system, it is productive in preparing students for the workforce--a workforce that requires students to have credentials from post-secondary acclaimed programs (thereby accepted).

Foucault (1994) argues that educational systems employ multiplicities of power in the form of: a) capacitive power (goal oriented, instrumental); b) power relations (between individuals and groups) and c) communication power (symbolic or written), constituting regulated systems that serve to support and overlap each other. For instance, capacitive power is evident in the regulations developed by faculty and administrators to govern higher education such as the processes for admission, development and delivery of curriculum, value attributed to levels of knowledge, determinants of students' success and consequence for non-compliance, to name a few. Post-secondary education system constitutes regulated systems given the abundance of power and influence that faculty members have in upholding curricular decisions versus the lack of students' influence in curriculum design, workload, assignments, and allocation of grades--all of which have implications on students' lives. Shor (1996) concurs that post-secondary institutions have a unilateral hierarchy where faculty have dominance and control over knowledge, while students have limited opportunities to give voice, or be heard.

Second, Foucault (1982) contends that within the context of culture, there are various ways in which people are objectified or transformed into subjects, dividing one from another in relation to value or significance. Such objectification of the advantaged versus less-advantaged may transcend to faculty members and students. For instance, faculty members may be perceived by students as having the greater advantage or power given their role in discerning grades. As such, students may be objectified by the grades they have received, a numeric indicator of performance that determines whether they will advance (success), or leave the academic system (fail), both of which have implications for their career aspirations.

Third, Foucault proposes that oppositions of power exist in relationships and people may resist the power that is closest to them or has an impact on them, when the status of the individual is challenged, or when power ignores who subjects are as individuals (Foucault, 1982). In keeping with this view, it is conceivable that students may view faculty members as the gatekeepers (power) over the rigor of a course, allocation of grades, and ultimately, their academic success. Some scholars contend that cyberbullying may be motivated by revenge in an attempt to right a perceived injustice (Gollwitzer, 2009; Hinduja \& Patchin, 2009, 2010; Raskauskas \& Stoltz, 2007; Sanders, 2009). It is plausible that students may feel disempowered with their lack of voice in faculty members' decisions and draw upon their technological savvy with online media to voice concern or worse, post defamatory comments about a faculty member, as a means of balancing power (Dooley, Pyżalski, \& Cross, 2009). It is conceivable that post-secondary students, frustrated with their academic stressors, may consider it easier to voice their frustrations via email, online faculty evaluation sites, or public faculty polling sites (e.g. Ratemyprofessor.com), than to engage in more constructive, albeit time consuming conflict resolution processes with a faculty member. For instance, the 
anonymity, ease of access, and permanence afforded by online media enables individuals to engage in behavior that might not otherwise be done in face-to-face interactions, creating a sense of invincibility for aggressors (Snakenborg, Van Acker, \& Gable, 2011; Suler, 2004; Willard, 2003).

\section{Design and Methods}

This two-stage sequential exploratory mixed methods study adopted an online survey, followed by individual interviews to capture faculty members' perceived experiences of cyberbullying by students. The design enabled examination of the social and relational complexities of this issue, which might not otherwise have been achieved using one solitary qualitative or quantitative approach (Bryman, Becker, \& Sempik, 2008; Creswell, 2008).

\subsection{Sample}

Purposeful convenience sampling was used to survey approximately 1040 faculty members from within one Canadian university during the winter term of 2012. An invitation and information pertaining to the study was distributed to currently employed faculty members via the institution's all faculty email distribution system. In accordance with stipulations set forth by the university, the online survey was held open for one month, and the anonymity of the institution preserved by use of a pseudonym (hereafter referred to as $X$ ). The institution was chosen based on the researcher's knowledge of the infrastructure, the constituents, and close connection to the subject matter. Most importantly, in recognition of the difficulty that some participants could encounter in disclosing, and thereby re-living their cyberbullying experiences, the research process was carefully considered. Discussing issues of victimization can be very difficult for some individuals and qualitative approaches provide a safe platform for individuals' voices to be heard in an environment conducive to their needs (Mishna \& Van Wert, 2013).

From the 36 faculty members who responded to the online survey $(3.4 \%, \mathrm{n}=36), 22$ participants reported to have encountered at least one cyberbullying incident in the past 24 months (hereafter referred to as cyberbullied faculty members) and were therefore allowed to complete the survey questions. From this group, 19 participants reportedly experienced at least one serious cyberbullying incident that had a negative effect on them. Four survey respondents self-selected and provided contact information to participate in an individual interview.

\subsection{Instrument}

Both the online survey and interview questions were adapted from previously validated research instruments examining: incivility and bullying of faculty in higher education (Lampman et al., 2009), faculty workplace bullying (Keashly \& Neuman, 2008; Keashly \& Neuman, 2010), and K-12 cyberbullying (Cassidy et al., 2009). Given the unique focus of this study, the aforementioned instruments were modified from their "bullying" and "student-targeted" focus to a "faculty-targeted cyberbullying" focus to capture faculty members' cyberbullying experiences. Prior to implementation, the survey instrument was reviewed by a panel of post-secondary workplace bullying and K-12 cyberbullying experts for content validity (modified Delphi method), then pilot tested for face validity.

The final revised survey consisted of 44 questions, including 34 closed-ended and 10 qualitative items to capture both factual and attitudinal information. Overall, the survey was divided into four sections including: the type, frequency, and duration of cyberbullying incidents; the participants' most serious cyberbullying experience; the impact of the experience; faculty members' response to cyberbullying, and finally, demographic questions. A definition of cyberbullying was provided in the letter of introduction and at the outset of the survey, to assist participants in understanding what types of behaviors constituted cyberbullying. As previously mentioned, this study described cyberbullying as aggressive, intimidating, derogatory, defamatory, or bullying messages sent to or about a faculty member by a student(s) via online media (e.g., cellular phone, email, and polling websites such as Ratemyprofessor.com [RMP]).

\subsubsection{Type, Frequency, and Duration of Incidents}

Participants were asked about the type of message that had been posted by the student(s), the online platform that had been used (e.g., email, faculty evaluation site), how often in the past 24 months it occurred, and how long it persisted.

\subsubsection{Faculty Members' Most Serious Cyberbullying Experience}

Several questions were asked about the participant's most serious cyberbullying experience, to illuminate the nature of 'serious' cyberbullying messages, in terms of the message content, frequency (e.g., single versus repeated incidents), and duration (e.g. one day versus a few weeks or months) of attacks. This study was also interested to explore the plausible precursors to faculty members' cyberbullying experiences (e.g., students' dissatisfaction with 
grades, assignment criteria), as well as information about the student in terms of whether the aggressor's identity, age, and gender was known.

\subsubsection{The Impact of Cyberbullying}

This section asked questions about the physical, psychological, relational, and professional implications of the participants' most serious cyberbullying experiences, followed by how long the effects persisted, what course of action was taken, and how satisfied they were with the course of action taken. This section closed with questions pertaining to the institutional support measures that were available to faculty members at the time of their most serious cyberbullying experience, and finally, participants were asked to list three top priority institutional support measures that would assist faculty members in managing cyberbullying effectively.

Finally, the last section of the survey afforded participants an opportunity to more fully disclose their experience by asking participating if they would like to participate in an individual interview with the researcher. Of the five faculty members who expressed interest and provided contact information, four faculty members completed the interview phase of the study. This brings the discussion about the research instrument and data collection to a close, and proceeds with the next stage involving data pertaining to research instrument, moving forward to the analysis of data, followed by the study findings.

\subsection{Analysis}

Descriptive statistical analyses were conducted on the online survey questionnaires using SPSS software, whereas the individual interview recordings were transcribed, member-checked with participants, then coded using a descriptive coding approach (Saldaña, 2009). This step was followed by re-coding of the data between three persons until all parties were satisfied that saturation had been achieved, reaching a total of 109 codes.

\section{Results}

\subsection{Descriptive Data}

As previously mentioned, from the 1040 faculty members at University $X$ (remains anonymous), who were invited to participate in the study, a total of 36 faculty members $(3.5 \%)$ responded to the online survey, from which 22 reportedly experienced at least one cyberbullying incident in the past 24 months, and 4 respondents participated in the individual interviews. Of the respondent faculty $(\mathrm{n}=36), 75 \%$ were female, $22 \%$ were male, $(3 \%$ did not indicate gender), and most held fulltime status. This study found that cyberbullied faculty members $(\mathrm{n}=22)$ were predominantly English speaking (97\%) Canadian citizens (72\%), female (68\%), and over 40 years of age (84\%) with more than 10 years of teaching experience in post-secondary education $(82 \%)$, which suggests that targeted faculty members were not novice to teaching.

These findings overlap with prior cyberbullying and workplace bullying research such that targeted individuals were predominantly female (Cassidy et al., 2012; Cassidy et al., 2014; Hinduja \& Patchin, 2012; Lampman, 2012; McKay et al., 2008), and as well with studies of post-secondary bullying (Keashly \& Neuman, 2008) and post-secondary cyber-harassment (Vance, 2010) reporting that targeted faculty members were commonly over 35 years of age. However findings from this study diverge from both Cassidy et al.'s (2014) report that bullied individuals were predominantly of racial or sexual minority (Cassidy et al., 2014), and studies of student-to-faculty incivility (Alberts, Hazen, \& Teobald, 2010; Alexander-Snow, 2004; Nilson \& Jackson, 2004) whereby young, non-white, and low-rank faculty members encountered more student-to-faculty incivility.

Interestingly, approximately $80 \%$ of the respondents reported that they knew the aggressors' identity, which suggests that some students chose not to conceal their identity despite the anonymity afforded by online platforms. Similar to prior post-secondary research (Dilmaç, 2009; Englander, 2008, Faucher et al., 2014) this study found that the perpetrators were predominantly male. The aggressors (69\%) commonly ranged from 22 to 29 years of age, most (44\%) were male acting alone, followed by female acting alone (25\%), then male and female as joint accomplices accounted for $19 \%$ of the incidents. Given the marginal amount of literature exploring gender within the context of student-to-faculty targeted cyberbullying, these findings suggest that further research exploring such gender differences is warranted.

\subsection{Cyberbullying Platforms and Message Content}

Similar to post-secondary cyberbullying study findings (Eskey et al., 2014b; Minor et al., 2013), from those who reported to have encountered at least one cyberbullying incident in the past 24 months $(n=22)$, cyberbullying incidents most commonly occurred "once or twice" $(75 \%, \mathrm{n}=22)$, and namely via email $(65 \%)$ or faculty polling sites (50\%). In terms of content, cyberbullying messages most commonly consisted of "disrespectful" (84\%), "aggressive 
or rude" (63\%), and "defamatory"(53\%) comments, in addition to "demands for higher grades" (62\%), "demands to reduce the difficulty of assignments" (59\%), and "confrontations toward the faculty member's authority" (50\%). Finally, when asked about their most recent cyberbullying experience, most respondents encountered cyberbullying "over one year ago" $(33 \%, n=22)$, followed by "within the past 6 months" $(29 \%)$.

In terms of the content of the cyberbullying messages, several key themes emerged from coding of the online survey text boxes and individual interviews. The messages were described as "angry", "inflammatory", "disrespectful, "rude", "offensive", 'threatening" and "bullying". The tone of cyberbullying email messages is depicted in both the interview participants' (hereafter referred to by $I P$ and their pseudonym) and survey respondents' (hereafter referred to by SRand and their corresponding \#) testimonials below:

The email messages...threatened to call the press, threatened to file a legal complaint...tried to intimidate me into changing the grade...to me that is bullying (IP Carol)

\section{I received several email messages referring to me as a bitch. (SR 9)}

While it is unsettling to know that targeted faculty members encountered such disrespectful and threatening behavior within their workplace, this phenomenon is not new, given similar findings have been reported in prior studies of classroom incivility (Alberts et al., 2010; Clark et al., 2012; DeSouza, 2010; Lampman et al., 2009; Vance, 2010), and more recent studies of post-secondary cyberbullying (Eskey et al., 2014b; Minor et al., 2013). For instance in a study of faculty members who teach online courses, Minor et al. (2013) found that faculty members cyberbullied via email with messages containing aggressive comments, threats of lawsuits, as well as public defamation in online platforms.

This study found that students' aggression towards faculty members was not confined to one domain, but rather crossed, as well as escalated between traditional (in-person) and virtual classroom boundaries. For instance, interview participant Andrew (pseudonym) reported receiving "angry email messages from a student" which escalated over a few weeks to "shouting and berating me during an exam". Similarly, Barbara (pseudonym) informed that after confronting a student about plagiarism, "I received several inflammatory...angry, angry email messages...and the behavior escalated to shouting and making defamatory comments towards me in an open office". Barbara added that although she is generally comfortable managing students' outbursts, she felt bothered by the level of aggression and persistence put forth by the student in attempt to sway the failing grade.

\subsection{Participants' Most Serious Cyberbullying Experience}

From those who encountered at least one cyberbullying incident in the last 24 months ( $n=22), 19$ faculty members reported to have experienced a serious cyberbullying incident that had a negative effect on them, and greater than $80 \%$ were "moderately" or "very bothered" by their most serious cyberbullying incident. From this group of respondents, most $(90 \%, \mathrm{n}=19)$ held fulltime appointments when the incident occurred. Notably, the most common precursors included "students' dissatisfaction with grades" (79\%), and the faculty member having to "address misconduct issues with the student" (32\%), which bear similarity to Minor et al. (2013) who also reported that students' dissatisfaction with grades precluded cyberbullying of online faculty members. In terms of message content, participants most commonly described their most 'serious' cyberbullying message(s) as disrespectful (90\%), aggressive or rude $(67 \%)$, defamatory $(56 \%)$, and demeaning (50\%). The explicit language, tone, and impact that a single unexpected anonymous email message can have on a targeted individual is depicted by the following survey respondents' testimonial:

An anonymous email was sent from a fabricated server...the address line was "fuk"(my first and lastnames@yahoo.ca"...claiming I marked students too hard...nobody gave a crap about what I was teaching them...threatening how students would treat me if they found me walking alone down the street...indicated that none other students from the class were watching [him or her] writing the email...I was extremely shaken by this email...I reported it...received absolutely no support. (SR 8)

The qualitative data from both the online surveys and individual interviews illuminated the methods employed by aggressors to elevate their marks. For instance, Carol (pseudonym) stated "some students use words in their messages to threaten or coerce me into changing their grade...to call the press". Similarly, Barbara (pseudonym) reported having received some "aggressive...angry, angry email messages" from a student who initially failed an assignment, was granted a resubmission, then plagiarized the re-write, resulting in a failing grade. Despite Barbara's attempts to engage and resolve the issue with the student, the students' aggression towards the faculty member escalated to in-person confrontations. According to Barbara, "the angry emails...it was harassment...it was repeated...and it escalated". 


\subsubsection{Impact}

The first main finding of this study concerns the type, duration, and impact of cyberbullying messages received by targeted faculty members, such that some participants experienced multiple (more than three) detrimental physical, emotional, relational, and professional effects that persisted from "a few days" to "more than one year". For example, in this study, the most common physical and emotional effects reported by respondents $(n=19)$ included "sleep disturbances" (74\%), "felt significantly anxious or distressed" (68\%), "felt depressed" (53\%), followed closely by "increased irritability" (47\%), "sudden emotional responses" (47\%), and "difficulty concentrating" (47\%), then "stress-related illnesses" (37\%). Approximately 50\% of the respondents reported fear and avoidance symptoms such as "tried not to think about the event" (58\%), "avoided the aggressor" (53\%), and "fear of being alone with the aggressor" (47\%). Of concern, some faculty members reported having "thoughts of retaliation" (26\%), and "thoughts of self- harm" (5\%). Finally, while most respondents $(85 \%)$ were "very bothered" by their cyberbullying experience, some respondents $(5 \%)$ perceived the cyberbullying incident to be a positive learning experience. Further, one respondent lamented that "it's a learning opportunity...students need to learn to behave respectfully".

The type of negative effects reported by study participants are consistent with prior research studies of traditional (offline) workplace bullying (Einarsen, Hoel, Zapf, \& Cooper, 2003; Keashly \& Harvey, 2005; Keashly \& Neuman, 2013; Kowalski, Morgan, \& Limber, 2012; Menesini \& Nocentini, 2012), academic workplace bullying (Kolanko et al., 2006; McKay et al., 2008), student incivility and contra-power harassment (Lampman, 2012; Lampman et al., 2009; Luparell, 2007), as well as K-12 and post-secondary cyberbullying (Beran \& Li, 2005; Beran et al., 2012; Cassidy et al., 2009; Minor et al., 2013). As well, in some studies, cyberbullied faculty members reported that the experience had a negative effect on work performance including their level confidence, ability to concentrate, productivity, and relationships with others, as well as their sense of safety (Cassidy et al., 2014; Faucher et al. 2014).

Qualitative data from the individual interviews shed light on the depth and breadth of the physical as well as emotional effects that were experienced by both male and female targeted faculty members. For instance, Debbie (pseudonym) became tearful upon disclosing how she reacted upon reading defamatory comments that had been posted to an online faculty evaluation site:

I felt sick to my stomach...lost sleep over it...it bothered me tremendously...my confidence was shattered...after all of these years of teaching...one comment left me feeling this way.

Similarly, male respondents, such as Andrew, exhibited physical signs (anxious, fidgeting) upon describing the thread of "angry email messages" that he had received from a student:

The whole thing was completely foreign to me...it was very upsetting...I felt threatened...shocked...I was just trying to help the student.

Thematic coding of the interview transcripts revealed that participants most commonly felt "surprised", "bothered or upset", "shocked", "shattered", "threatened", "defenseless" and "disappointed", about their most serious cyberbullying experience. Physical and emotional responses varied between participants, ranging from symptoms of anxiety (restlessness, fidgeting, looking down at the floor, avoiding eye contact) at the onset of the interview, to more emotional responses (e.g., tears, sadness, raised tone of voice, openly crying) as the interview progressed. For instance, while Debbie appeared calm at the onset of the interview, more emotions surfaced (e.g., tears, elevated tone of voice) as she described the moment of opening the results of an online faculty evaluation:

I was away on vacation...sitting in a coffee shop...opened the evaluation...read one of the comments and I was shocked. There were a few people in close proximity to me...I really felt physically ill with the one comment...I felt tears coming. A woman sitting across from me leaned over [said] "Oh no...you've just received some really bad news"... I just got up and left...couldn't stop thinking about it...it's bothering me again now...those powerful emotions.

Further to the emotional effects reported, common themes pertaining to negative effects included flashbacks in the form of "recurring memories", and rationalizing or sanitizing the situation by "minimizing the incident", as depicted by Debbie in the following excerpt:

At first I thought I was over-reacting...it wasn't as bad as what happens to other people...I didn't think I was affected, but I was affected (tearful)...I have a lot of experience and should be able to handle it...one bad comment...by a disgruntled student had such an effect on me...I was fine until this interview...it's like reliving it again (crying)...I have to put it behind me. 
This study also found that the duration of negative effects varied in persistence from "a few days" to "greater than one year". Further, some participants experienced multiple (three or more) negative effects such as "had difficulty sleeping", "increased irritability", "sudden emotional responses when reminded of the incident", "felt significantly anxious or distressed" for several weeks or months. This begs the question as to how faculty members, experiencing these negative effects were able to cope both during and after the incident?

Notably, while this was not designed as a psychologically based study, the aforementioned findings prompted review of the literature, and found that combined, the type and duration of negative effects reported by some participants resembled the Acute Stress Disorder (ASD) and Post Traumatic Stress Disorder (PTSD) criteria as set forth by the American Psychiatric Association DSM-IV TR ${ }^{\mathrm{TM}}$ (2000). For instance, approximately 25\% $(\mathrm{n}=19)$ reported having three or more negative effects that persisted for one to eight weeks (e.g., felt significantly anxious or distressed, depressed, increased irritability, sudden emotional responses when reminded of the event, fear of the aggressor, avoidance of the aggressor or reminders of the incident, felt depressed) which bear resemblance to the APA

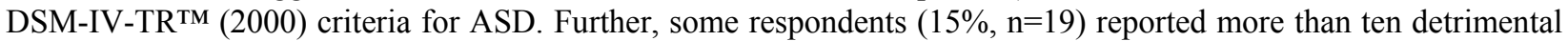
effects that persisted for longer than one year after their most serious cyberbullying experience. It is important to mention that the survey instrument for this study was not designed to test for ASD or PTSD symptoms, yet given the type and duration of symptoms, it is plausible that respondents who reported multiple symptoms that persisted for "2-5 months", "6-12 months", and "more than one year" may have experienced ASD or PTSD. Moreover, reported "thoughts of retaliation" $(21 \%, \mathrm{n}=19)$ and "thoughts of self-harm" $(5 \%)$ pose concern given that acting on such thoughts could be highly detrimental for the overall campus community.

Of further consideration, cyberbullied faculty members are likely to be situated somewhere on the processing / healing continuum, while fulfilling their teaching responsibilities. This raises the question as to how a faculty member, affected by cyberbullying, would manage the day-to-day tensions that can arise in the process of teaching, or how they would manage the notion of a known or suspected cyber-aggressor in their midst? For instance, it is feasible that a faculty member who teaches across multiple cohorts of a four-year program may encounter student aggression in one term, and be exposed to the aggressor in subsequent terms. If the student-faculty tensions are not resolved, the implications on the faculty member, student, and learning environment are formidable. Putting these findings into context, the prevalence rates of plausible PTSD are relatively low compared to those reported in a Canadian epidemiological study (Van Ameringen, Mancini, Patterson, \& Boyle, 2008) which cited $9.2 \%$ for chronic or "lifetime" PTSD, and 2.4\% for "current" (one month) PTSD.

The qualitative data shed light on the faculty-student relationship as targeted faculty members' discussed the connection they attempted to forge with students. For instance, some interview participants became emotional when describing their investment in establishing a positive, supportive relationship with students, and subsequent despair upon being cyberbullied. Interview participants commonly described feeling "shocked", "surprised", and "disbelief" that they had been cyberbullied - namely due to their belief that they had a positive working relationship with the student and were trying to help the student in providing constructive feedback to assist them in learning. The following testimonials shed light on this perspective:

For me...I try to look for the good in people...I was a little unsure about how to interact and react with that student and other students after that [angry email] incident...I thought I had a good rapport with students.(IP Andrew)

I meet with the students...discuss their marks... and give them constructive feedback to prepare them for the higher level of writing for their upcoming semester...I don't give out A's unless their performance is exceptional...the student wrote that I was the worst teacher they ever had...I was lazy...I was shocked. (IP Debbie)

When a student sends an angry email, I choose not to respond to the email but to wait and bring them into a one-to-one conversation to resolve the problem...try to reframe it in a way that says, "while you are angry, you would be far better to communicate in a more appropriate way when you are frustrated, so I hope this is a learning experience for you... but this student..the situation was escalating...it was harassment (IP Barbara)

In terms of the relational consequences experienced by cyberbullied faculty members, a breakdown in their relationships with students ranked highest (74\%), followed by colleagues (32\%), Deans and administrators (32\%), as well as family members (32\%), then friends (11\%). Professional ramifications most commonly included loss of desire to go to work (68\%), followed by loss of productivity at work (53\%). Loss of confidence was also reported with regard to managing student conflict (47\%), working with students $(42 \%)$, or teaching students (37\%), while $53 \%$ felt like quitting their job. These findings bear similarity to prior studies of contra-power harassment, student 
incivility (Lampman et al., 2009; Luparell, 2007), and workplace bullying (McKay et al., 2008), which also reported loss of confidence and loss of desire to go to work on the outset of being bullied.

\subsubsection{Action Taken}

Further to learning about the impact of cyberbullying on targeted faculty members, this study also sought to identify targeted faculty members' awareness of cyberbullying and the action taken. Approximately $58 \%$ of the respondents $(n=19)$ thought they could recognize signs that cyberbullying might occur, or knew how to report such incidents $(53 \%)$, knew about cyber-aggression, harassment, or bullying $(47 \%)$, yet fewer knew what policy or procedure to follow $(32 \%)$, or had training in managing student misconduct $(16 \%)$. Moreover, approximately $70 \%$ of the respondents reported that students can get away with cyberbullying at the institution of study. These findings suggest a gap in institutional resources such as cyberbullying education, institutional policy, and procedures to address the issue--consistent with K-12 and post-secondary cyberbullying studies (Eskey et al., 2014b; Kowalski, Limber, \& Agatston, 2008; Minor et al., 2013; Ševčíková \& Šmahel, 2009; Ybarra \& Mitchell, 2004).

When provided with a list of plausible responses to their cyberbullying incident, participants most commonly consulted with colleagues (84\%), friends (74\%), an immediate supervisor $(74 \%)$, or reviewed institutional policies or procedures $(58 \%)$. Fewer reported the incident to a senior administration $(37 \%)$, or campus security $(32 \%)$, while a smaller percentage attempted to resolve the incident with the student(s) $(42 \%)$. Of all the approaches attempted, connecting with colleagues, friends, and immediate supervisors were reported as the most successful (45\%), while few $(5 \%)$ were successful in attempting to resolve the incident the aggressor.

Consistent with studies of workplace bullying and post-secondary cyberbullying (Boice, 1996; Luparell, 2004; Minor et al., 2013), some participants (45\%) did not report their cyberbullying experience. The rationale for not reporting cyberbullying included concern that complaints would not be taken seriously; that messages would not be viewed by others as bullying; that faculty would be viewed as incompetent, and finally, fear of further victimization by students or administrators. It is also possible that underreporting stems from a lack of awareness about cyberbullying, as depicted in the following online survey and individual interview testimonials below. These findings have also emerged in studies of post-secondary workplace bullying (McKay et al., 2008), student incivility (Lampman et al., 2009; Luparell, 2007) and post-secondary cyberbullying (Cassidy et al., 2014; Eskey et al., 2014b; Faucher et al., 2014; Minor et al., 2013), which suggests that further inquiry is needed to better understand the deterrents for reporting cyberbullying incidents, and thereby determine feasible remedies.

I didn't report it...didn't know who to report the incident to...or if there was any point. (SR 19)

I did not report it...had fear of further victimization. Administrators may not act on it, or if they do...may be detrimental to the faculty member who reports it. (SR 23)

Nasty comments on faculty rating cites are probably not considered bullying by others...one is meant to suck it up and not care. (SR 20)

It wasn't super horrible, and I don't know if it was (long pause)...bullying...even participating in this study, I wasn't sure what constitutes cyberbullying... it really bothered me...so I think it fits. (IP Debbie)

\subsubsection{Support Measures Needed to Manage Cyberbullying}

In this study, most participants (79\%) reported that students at the institution of study can get away with cyberbullying, $11 \%$ agreed that support measures are easy to access, and fewer (11\%) agreed that the existing support measures are effective. Common theme1) clearly written, well-communicated institutional cyberbullying policy and sanctions that both inform and deter such behavior, 2) cyberbullying education for faculty members and students (informing what constitutes cyberbullying, what to expect, how to prevent it and how to respond in the immediacy of the incident), and 3) counseling services for targeted individuals with a contact person for formal cyberbullying complaints. s from the transcripts consisted of gaps in institutional policy, cyberbullying education, and accessible support services, all of which deter participants from preventing or managing cyberbullying effectively. The lack of resources available to faculty members, compounded by the harmful effects incurred from cyberbullying were also an expressed concern. For instance, participants reported:

There isn't anything that I know of about cyberbullying, or misuse of Facebook, or the consequences. Faculty need to know what to do when students invite them into these platforms... When teachers are hired they should have training...it is important to know that faculty members are supported when they feel threatened. (IP Andrew) 
Our policy language is far too broad...difficult to apply...current process is not effective...if cyberbullying were a new policy...it would be sent out by email for review...faculty are overwhelmed with all the email messages...can't learn a policy with a two-minute window to review it...understand it, or put it into effective practice... Cyberbullying is very complicated...has a lot of implications on the person who experiences it (IP Carol)

Policy and procedure is nothing if we don't educate our faculty members on what it [cyberbullying] is and what to do about it. (IP Barbara)

From the voices of study participants, the three highest priority institutional support measures needed to assist targeted faculty members in managing cyberbullying incidents include: 1) clearly written, well-communicated institutional cyberbullying policy and sanctions that both inform and deter such behavior, 2) cyberbullying education for faculty members and students (informing what constitutes cyberbullying, what to expect, how to prevent it and how to respond in the immediacy of the incident), and 3) counseling services for targeted individuals with a contact person for formal cyberbullying complaints. Consistent with the literature (Alberts et al., 2010; Cassidy et al., 2009), participants also expressed the need for a process to commence dialogue amongst campus constituents to expose, manage, and prevent cyberbullying behaviors. These recommendations align with former post-secondary cyberbullying studies in terms of the support needed for victims, well communicated institutional policy developed in consultation with campus constituents, and a more respectful workplace environment (Cassidy et al., 2014; Faucher et al., 2014). Yet given the limited research on student-to-faculty targeted cyberbullying, further research would be needed to understand the breadth and depth of support services that would be useful in preparing faculty members to manage cyberbullying effectively.

\section{Discussion}

\subsection{Study Limitations}

Three predominant limitations of this study include the low response rate, unique focus, and implementation date. First, the low response rate $(\mathrm{N}=1040)$ from the online survey $(3.5 \%, \mathrm{n}=36)$ and the interviews $(.38 \%, \mathrm{n}=4)$ could be attributed to faculty members' lack of awareness of what constitutes cyberbullying, the prevalence of cyberbullying at this institution, or the sensitivity of the subject matter. Cyberbullied individuals may be reluctant to participate for a variety of reasons, including fear of repercussions. For instance one survey respondent aptly stated "Sometimes you just can't tell people about these kinds of incidents...you have to be really careful about who you tell and what you say". Understandably, cyberbullied faculty members may be deterred by the possibility that participation may invoke painful memories of a difficult experience. Secondly, given the study's unique focus to one sample (faculty members) within one institution of currently employed faculty members, the findings are neither generalizable to other campus constituents, nor to other post-secondary institutions. Third, the survey implementation was restricted to 30 days as stipulated by the institution, possibly delimiting faculty members who may have been on leave. Finally, participants' cyberbullying experiences were not verified by the alleged aggressor(s), nor were the respondents asked to provide copies of the cyberbullying messages received.

While the number of respondents is small, the qualitative and quantitative information generated some compelling findings, which satisfied the purpose of the study and answered the research questions. The detailed information provided by the survey and interview participants' narratives illuminated the type, severity, and impact of their cyberbullying experiences, but more so, the magnitude of harm incurred by cyberbullied faculty members. Witnessing such emotional testimony affirmed that the participants' experiences were not only serious, but had profoundly negative implications for some individuals.

\subsection{Implications and Recommendations}

This study acknowledges that cyberbullying behavior rests with the individual and manifests as tension between faculty members and students within the context of post-secondary institutions. The complex nature of this phenomenon may be intertwined with the roles and responsibilities held of faculty members to make decisions that affect students' lives, within an institutional system that affords few opportunities for students to influence the factors that gauge evaluation of their performance. When asked what institutional support measures need to be in place to address cyberbullying in post-secondary education, the participants' top three priorities included first, clearly written, well-communicated institutional cyberbullying policy and procedures, followed by education for faculty and students (e.g., what constitutes cyberbullying, how to prevent and respond), and support services (e.g., counseling, focus groups) for those who have participated in or have encountered cyberbullying. Faculty need reliable, readily 
available resources to equip themselves with the skills to manage cyberbullying confidently, competently, and effectively.

Further exploration of the underpinnings of cyberbullying may also assist in problem solving. For instance, knowing that students' dissatisfaction with grades was the most common precursor to participants' cyberbullying experiences, suggests that it may be beneficial for faculty members to connect students with support services in the early onset of academic or personal distress. Faculty members can initiate meeting face-to-face with students to convey support, approachability, and willingness to engage in dialogue to greater understand students' concerns. This creates a foundation for a collaborative student-faculty working relationship, where students can be actively involved in determining evaluation strategies for assignments, negotiating grades, and accessing institutional supports aligned with their needs - thereby shifting the perceived power imbalance from a faculty-driven curriculum to a student-focused approach (e.g., involve students in the evaluation process, provide marking rubrics that are understandable and compatible with students' individual learning styles). Further, embedding cyberbullying education into the curriculum provides a platform for students and faculty to dialogue and problem solve this phenomenon. After all, we know that cyberbullying exists in the K-12 sector, graduates to post-secondary, and extends beyond to the workplace sector.

Moreover, the fundamental solution for cyberbullying rests with recognizing that cyberbullying is a chosen behavior, understanding the motivators, and shifting one's capacity to more caring ways of being. In the student-faculty relationship, it is equally important to develop faculty members' ability to recognize and respond to cyberbullying with competence and confidence. When student-faculty tensions arise, just as students' coping mechanisms or resilience may be tapped to the point of exhaustion or desperation, faculty members may also be tapped in their ability to respond. To foster a healthy student-faculty relationship, it is imperative that institutional leaders develop greater understanding of, and acknowledge students' distress, as well as equip students with resources and the skill base to navigate the personal and academic stressors likely to be encountered in their journey through higher education. Preparing students and faculty to draw upon the constructs of emotional intelligence and resilience not only affords students the foundation to navigate frustrations and engage in dialogue with faculty, but further affords faculty members ' the ability to mitigate student discourse in a collaborative manner.

At the time of this study (2012) there were gaps in the resources available at the institution of study to guide faculty members (e.g., clearly written, well-communicated institutional policy and procedure, cyberbullying education) in managing cyberbullying. To the credit of study participants' testimonials, findings from this study have affected change at various levels across the institution. For instance, the reported gap in cyberbullying education and cyberbullying policy not only enhanced awareness but opened dialogue at the institutional policy committee level to explore policy pertaining to cyberbullying, harassment, and bullying. Further, the study findings served to enhance faculty members' awareness of the issue, the impact, and the recommendations that were put forth by study participants. As well, the faculty association implemented a cyberbullying focus group to learn from and support cyberbullied faculty members along their pathway toward healing. In the interest of enhancing faculty and students' awareness, cyberbullying education has been embedded into some aspects of the curriculum, thereby providing a platform for students and faculty members to dialogue about this phenomenon. Finally, in the interest of fostering a caring environment, various self-care practices (e.g., meditation, yoga, and mindfulness) have also been implemented within some courses to introduce and actively engage students in various modalities of healing to optimize students' resilience and manage stress prior to midterm and final exam periods.

\subsection{Significance}

Over the past two years, cases have come before Canadian courts that involve faculty members who were cyberbullied by students. Given the growth of cyber communication over the past decade and the implications of cyber-bulling at the individual, relational, organizational, and systems levels - the need for further cyber-bullying research and the impact on victims is warranted. Although the response rate was small, the quantitative and qualitative data generated some compelling findings which warrant further exploration across other post-secondary institutions, with some refinements to the instrument. Second, given the detrimental effects that were reported by respondents, psychologically focused approaches could enhance understanding of these effects, as well as to explore the support measures that would be beneficial to targeted individuals. Finally, it would be interesting to explore the student-to-faculty cyberbullying from the aggressor's perspective, broadening the interaction of agents-findings which could further enrich the cyberbullying in post-secondary education literature, and understanding of the phenomenon. 
This research study adds to the scope of cyberbullying research within the academic and workplace contexts. Further, the study is unique in having adapted prior research study instrumentation, blending quantitative and qualitative approaches including individual interviews, with the intent focus of capturing faculty members' experiences with cyberbullying by students in the post-secondary sector. Study findings serve to not only expose and enhance understanding of the complexity of this phenomenon, but provide a foundation from which post-secondary administrators can develop institutional policy and education programs to address this issue.

\section{Acknowledgements}

This research study is dedicated to the faculty members who, in taking the risk to disclose their difficult cyberbullying experiences, have exposed and illuminated our understanding of this phenomenon. Gratitude is extended to Dr. Michelle Nilson, Dr. Wanda Cassidy, Dr. Margaret Jackson, and Dr. Chantel Faucher who assisted in the process of this research study. Thank you to Dr. S. Lampman, Dr. L. Keashly, Dr. J. Neuman, and Dr. K. McDevitt for conducting scholarly review of the survey instrument, and to Maggie Karpilovsky for participating in the coding of qualitative data.

\section{References}

Agatson, P., Kowalski, R., \& Limber, S. (2012). Youth views on cyberbullying. In J.W. Patchin \& S. Hinduja (Eds.), Cyberbullying prevention and response: Expert perspectives. (pp. 57-71). New York: Routledge.

Alberts, H. C., Hazen, H. D., \& Teobald, R. B. (2010). Classroom incivilities: The challenge of interactions between college students and instructors in the US. Journal of Geography in Higher Education, 34, 439-462. http://dx.doi.org/10.1080/03098260903502679

Alexander-Snow, M. (2004). Dynamics of gender, ethnicity, and race in understanding classroom incivility. New Directions for Teaching and Learning, 99, 21-31. http://dx.doi.org/10.1002/tl.155

Beale, A. V., \& Hall, K. R. (2007). Cyberbullying: What school administrators (and parents) can do. Clearing House, 81(1), 8-12. http://dx.doi.org/10.3200/TCHS.81.1.8-12

Belsey, B. (2008). Cyberbullying: An emerging threat to the always on generation. Retrieved from http://www.cyberbullying.ca/pdf/Cyberbullying_Article_by_Bill_Belsey.pdf

Beran, T., \& Li, Q. (2005). Cyber-harassment: A study of a new method for an old behaviour. Journal of Educational Computing Research, 32(3), 265-277. http://dx.doi.org/10.2190/8YQM-B04H-PG4D-BLLH

Beran, T., \& Li, Q. (2007). The relationship between cyberbullying and school bullying. Journal of Student Wellbeing, 1(2), 15-33. Retrieved from http://www.ojs.unisa.edu.au/index.php/JSW/article/viewFile/172/139

Beran, T., \& Lupart, J. (2009). The relationship between school achievement and peer harassment in Canadian adolescents: The importance of mediating factors. School Psychology International, 30(1), 75-91. http://dx.doi.org/10.1177/0143034308101851

Beran, T., Rinaldi, C., Bickham, D. S., \& Rich, M. (2012). Evidence for the need to support adolescents dealing with harassment and cyber-harassment: Prevalence, progression, and impact. School Psychology International, 33(5), 562-576. http://dx.doi.org/10.1177/0143034312446976

Boice, R. (1996). Classroom incivilities. Research In Higher Education, 37(4), 453-485. http://dx.doi.org/10.1007/BF01730110

Brown, K., Jackson, M., \& Cassidy, W. (2006). Cyber-bullying: Developing policy to direct responses that are equitable and effective in addresssing this special form of bullying. Canadian Journal of Educational Administration and Policy, 57, 1-35. https://umanitoba.ca/publications/cjeap/articles/brown_jackson_cassidy.html

Bryman, A., Becker, S., \& Sempik, J. (2008). Quality criteria for quantitative, qualitative, and mixed methods research: A view from social policy. International Journal of Social Research Methodology, 11(4), 261-276. http://dx.doi.org/10.1080/13645570701401644

Campbell, M. A. (2005). Cyber bullying: An old problem in a new guise? Australian Journal of Education, 15(1), 68-76. http://dx.doi.org/10.1375/ajgc.15.1.68

Cassidy, W., Brown, K., \& Jackson, M. (2011). Moving from cyber-bullying to cyber-kindness: What do students, educators and parents say? In E. Dunkels, G.M. Franberg, \& C. Hallgren (Eds.), Youth culture and net culture: Online social practices (pp. 256-277). Hershey, NY: Information Science Reference. http://dx.doi.org/10.2190/EC.46.4.f 
Cassidy, W., Brown, K., \& Jackson, M. (2012). 'Under the radar': Educators and cyberbullying in schools. School Psychology International, 33(5), 520-532. http://dx.doi.org/117/0143034312445245

Cassidy, W., Faucher, C., \& Jackson, M. (2013). Cyberbullying among youth: A comprehensive review of current international research and its implications and application to policy and practice. School Psychology International, 34(6), 575-612. http://dx.doi.org/10.1177/0143034313479697

Cassidy, W., Faucher, C., \& Jackson, M. (2014). The dark side of the ivory tower: Cyberbullying of university faculty and teaching personnel. Alberta Journal of Educational Research, 60(2), 279-299. Retrieved from http://ajer.journalhosting.ucalgary.ca/index.php/ajer/article/view/1250

Cassidy, W., Jackson, M., \& Brown, K. (2009). Sticks and stones can break my bones, but how can pixels hurt me?: Students' experiences with cyber-bullying. School Psychology International, 30, 383-401. http://dx.doi.org/10.1177/0143034309106948

Clark, C. M., Faan, A., Werth, L., \& Ahten, S. (2012). Cyber-bullying and incivility in the online learning environment, Part 1: Addressing faculty and student perceptions. Nurse Educator, 37(4), 150-156. http://dx.doi.org/10.1097/NNE.0b013e31825a87e5

Creswell, J. W. (2008). Collecting qualitative data. In J. W. Creswell (Ed.), Educational research: Planning, conducting, and evaluating quantitative and qualitative research (3rd ed., pp. 213-242). Upper Saddle River, NJ: Pearson Merrill Prentice Hall.

Crosslin, K., \& Golman, M. (2014). "Maybe you don't want to face it"-College students' perspectives on cyberbullying. Computers in Human Behavior, 41, 14-20. http://dx.doi.org/10.1016/j.chb.2014.09.007

Daniloff, D. (2009). Cyberbullying goes to college. Bostonia University. Retrieved from http://www.bu.edu/bostonia/spring09/bully/

DeSouza, E. R. (2010). Frequency rates and correlates of contrapower harassment in higher education. Journal of Interpersonal Violence, 48(11), 1-27. http://dx.doi.org/10.1177/0886260510362878

Dickerson, D. (2005). Cyberbullies on campus. University of Toledo Law Review, 31, 51. Retrieved from http://p7888-godot.lib.sfu.ca.proxy.lib.sfu.ca

Dilmaç, B. (2009). Psychological needs as a predictor of cyber bullying: A preliminary report on college students. Educational Sciences: Theory \& Practice, 9(3), 1307-1395. Retrieved from http://eric.ed.gov/?id=EJ858926

Dooley, J., Gradinger, P., Strohmeier, D., Cross, D., \& Spiel, C. (2010). Cyber-victimisation: The association between help-seeking behaviours and self-reported emotional symptoms in Australia and Austria. Australian Journal of Guidance \& Counselling, 20(2), 194-209. http://dx.doi.org/10.1375/ajgc.20.2.194

Dooley, J., Pyżalski, J., \& Cross, C. (2009). Cyberbullying versus face-to-face bullying. Zeitschrift für Psychologie / Journal of Psychology, 217(4), 182-188. http://dx.doi.org/10.1027/0044-3409.217.4.182

Einarsen, S., Hoel, H., Zapf, D., \& Cooper, C. L. (2003). The concept of bullying at work. In S. Einarsen, H. Hoel, D. Zapf, \& C. L. Cooper (Eds.), Bullying and emotional abuse in the workplace: International perspectives in research and practice (pp. 3-30). London: Taylor \& Francis.

Englander, E. K. (2008). Cyberbullying and information exposure: User-generated content in post-secondary education. In MARC Publications. Paper 11, 1-20. Retrieved from http://vc.bridgew.edu/marc_pubs/11

Eskey, M., Taylor, C., \& Eskey, M. (2014a). Cyber-bullying in the online classroom: Instructor perceptions of aggressive student behavior. Online Journal of Distance Learning Administration, 17(4). Retrieved from https://www.westga.edu/ distance/ojdla/winter174/eskey_taylor_eskey174.html

Eskey, M., Taylor, C., \& Eskey, M. (2014b). Cyberbullying in the online classroom: Faculty as the targets. TCC Worldwide Online Conference, 17(4), 30-41. Retrieved from https://www.westga.edu/ distance/ojdla/winter174/eskey_taylor_eskey174.html

Faucher, C., Jackson, M., \& Cassidy, W. (2014). Cyberbullying among University students: Gendered experiences, impacts, and perspectives. Education Research International. http://dx.doi.org/10.1155/2014/698545

Faucher, C., Jackson, M., \& Cassidy, W. (2015). From the sandbox to the inbox: Comparing the acts, impacts, and solutions of bullying in K-12, higher education, and the workplace. Journal of Education and Training Studies, 3(6), 111-125. http://dx.doi.org/10.11114/jets.v3i6.1033 
Finn, J. (2004). A survey of online harassment at a university campus. Journal of Interpersonal Violence, 19(4), 468-483. http://dx.doi.org/10.1177/0886260503262083

Foucault, M. (1977). Discipline and punish: The birth of prison. New York: Pantheon.

Foucault, M. (1982). The subject and power. Critical Inquiry, 8(4), 777-795. http://dx.doi.org/10.1086/448181

Francisco, S. M., Simão, A. M., Ferreira, P. C., \& das Dores Martins, M. J. (2015). Cyberbullying: The hidden side of college students. Computers in Human Behavior, 43, 167-182. http://dx.doi.org/10.1016/j.chb.2014.10.045

Glover, D., Gough, G., Johnson, M., \& Cartwright, N. (2000). Bullying in 25 secondary schools: Incidence, impact and intervention. Educational Research, 42(2), 141-156. http://dx.doi.org/10.1080/001318800363782

Gollwitzer, M. (2009). Justice and revenge. In M. E. Oswald, S. Bieneck, \& J. Hupfeld-Heinemann (Eds.), School psychology of punishment of crime (pp. 137-156). Hoboken, NJ: Wiley.

Grigg, D. W. (2010). Cyber-aggression: Definition and concept of cyberbullying. Australian Journal of Guidance \& Counselling, 20(2), 143-156. http://dx.doi.org/10.1375/ajgc.20.2.143

Hinduja, S., \& Patchin, J. W. (2007). Offline consequences of online victimization: School violence and delinquency. Journal of School Violence, 6(3), 89-112. http://dx.doi.org/10.1300/J202v06n03_06

Hinduja, S., \& Patchin, J. W. (2008). Cyberbullying: An exploratory analysis of factors related to offending and victimization. Deviant Behavior, 29(2), 129-156. http://dx.doi.org/10.1080/01639620701457816

Hinduja, S., \& Patchin, J. W. (2009). Bullying beyond the school yard: Preventing and resonding to cyberbullying. Thousand Oaks, CA: Sage Publications.

Hinduja, S., \& Patchin, J. W. (2010). Bullying, cyberbullying, and suicide. Archives of Suicide Research, 14(3), 206-221. http://dx.doi.org/10.1080/13811118.2010.494133

Hinduja, S., \& Patchin, J. W. (2012). School climate 2.0: Preventing cyberbullying and sexting one classroom at a time. Thousand Oaks, CA: Corwin

Hoel, H., \& Cooper, C. L. (2000). Destructive conflict and bullying at work. Retrieved from http://scholar.google.com.proxy.lib.sfu.ca/scholar

Jones, J. C., \& Scott, S. (2012). Cyberbullying in the university classroom: A multiplicity of issues. In L. A. Wankel \& C. Wankel (Eds.), Misbehavior online in higher education: Cutting-edge technologies in higher education (pp. 157-182). Bingley, UK: Emerald. http://dx.doi.org/10.1108/S2044-9968(2012)0000005011

Keashly, L., \& Harvey, S. (2005). Emotional abuse in the workplace. In S. Fox \& P. Spector (Eds.), Counterproductive work behaviors (pp. 201-236). Washington: American Psychological Association.

Keashly, L., \& Neuman, J. H. (2008). Minnesota State University Mankato final report: Workplace behavior (bullying) project survey. (pp 1-29) Minnesota State University, Mankato.

Keashly, L., \& Neuman, J. H. (2010). Faculty experience with bullying in higher education. Administrative Theory \& Praxis, 32(1), 48-70. http://dx.doi.org/10.2753/ATP1084-1806320103

Keashly, L., \& Neuman, J. H. (2013). Bullying in higher education: What current research, theorizing, and practice tell us. In J. Lester (Ed.), Workplace bullying in academia. New York, NY: Routledge. Retrieved from http://www.amazon.ca/s/ref=nb

Kolanko, K., Clark, C., Heinrich, K. T., Olive, D., Serembus, J. F., \& Sifford, K. S. (2006). Academic dishonesty, bullying, incivility, and violence: Difficult challenges facing nurse educators. Nursing Education Perspectives, 27(1), 34-42. Retrieved from http://web.ebscohost.com.proxy.lib.sfu.ca

Kowalski, R. M., Limber, S. P., \& Agatston, P. W. (2008). Cyber Bullying: The new moral frontier. Oxford, UK: Blackwell Publishing Ltd. http://dx.doi.org/10.1002/9780470694176

Kowalski, R. M., Limber, S. P., \& Agatston, P. W. (2012). Cyberbullying: Bullying in the digital age (2nd ed.). Malden, MA: Wiley-Blackwell.

Kowalski, R. M., Morgan, C. A., \& Limber, S. P. (2012). Traditional bullying as a potential warning sign of cyberbullying. School Psychology International, 33(5), 505-519. http://dx.doi.org/10.1177/0143034312445244

Lampman, C. (2012). Women faculty at risk: U.S. professors report on their experiences with student incivility, Bullying, Aggression, and Sexual Attention. NASPA Journal About Women in Higher Education, 5(2), 184-208. http://dx.doi.org/10.1515/njawhe-2012-1108 
Lampman, C., Phelps, A., Bancroft, S., \& Beneke, M. (2009). Contrapower harassment in academia: A survey of faculty experience with student incivility, bullying, and sexual attention. Sex Roles, 60, 331-346. $\mathrm{http}: / / \mathrm{dx}$. doi.org/10.1007/s11199-008-9560-x

Lester, J. (Ed.) (2013). Workplace bullying in higher education. New York: Routledge. Retrieved from http://www.amazon.ca/s/ref=nb

Lewis, D. (2004). Bullying at work: The impact of shame among university and college lecturers. British Journal of Guidance \& Counselling, 32(3), 281-289. http://dx.doi.org/10.1080/03069880410001723521

Li, Q. (2007). New bottle but old wine: A research of cyberbullying in schools. Computers in Human Behaviour, 23(4), 1777-1791. http://dx.doi.org/10.1016/j.chb.2005.10.005

Luparell, S. (2004). Faculty encounters with uncivil nursing students: An overview. Journal of Professional Nursing, 20, 59-67. http://dx.doi.org/10.1016/j.profnurs.2003.12.007

Luparell, S. (2007). The effect of student incivility on nursing faculty. Journal of Nursing Education, 46(1), 7-14. Retrieved from http://p7888-godot.lib.sfu.ca.proxy.lib.sfu.ca/

McKay, R., Arnold, D., Fratzl, J., \& Thomas, R. (2008). Workplace bullying in academia: A Canadian study. Employee Responsibility and Human Rights Journal, 20, 77-100. http://dx.doi.org/10.1007/s10672-008-9073-3

Menesini, E., \& Nocentini, A. (2012). Peer education intervention: Face-to-face versus online. In A. Costabile \& B. A. Spears (Eds.), The impact of technology on relationship in educational settings (pp. 139-150). New York: NY: Routledge.

Minor, M. A., Smith, G. S., \& Brashen, H. (2013). Cyberbullying in higher education. Journal of Educational Research and Practice, 3(1). doi:10.5590/JERAP.2013.03.1.02

Mishna, F., \& Van Wert, M. (2013). Qualiative studies. In S. Bauman, D. Cross, \& J. Walker (Eds.), Principles of cyberbullying research: Definitions, measures, and methodology (pp. 5571-6080). New York, NY: Routledge.

Molluzzo, J. C., Lawler, J. (2014). A comparison of faculty and student perceptions of cyberbullying. Information Systems Educational Journal 12(2), 47-63. Retrieved from http://isedj.org/2014-12/

Monks, C. P., Robinson, S. R., \& Worlidge, P. (2012). The emergence of cyberbullying: A survey of primary school pupils' perceptions and experiences. School Psychology International, 33(5), 477-491. http://dx.doi.org/10.1177/0143034312445242

Na, H., Dancy, B. L., \& Park, C. (2015). College student engaging in cyberbullying victimization: Cognitive appraisals, coping strategies, and psychological adjustments. Archives of Psychiatric Nursing. http://dx.doi.org/10.1016/j.apnu.2015.01.008

Nardone, J. (2010). Universtiy of Calgary students win facebook freespace battle. Retrieved from $\mathrm{http}: / / \mathrm{j}$-source.ca/article/university-calgary-students-win-facebook-free-speech-battle

Nicoletti, J., \& Spencer-Thomas, S. (2010). Violence 101: Understanding the basics. In J. Nicoletti, S. Spencer-Thomas, \& C. Bollinger (Eds.), Violence goes to college: The authoritative guide to prevention and intervention (2nd ed., pp. 26-31). Springfield: Charles C. Thomas Publishers, Ltd.

Nilson, L. B., \& Jackson, N. S. (2004). Combating classroom misconduct (incivility) with Bill of Rights. Paper presented at the International Consortium for Educational Development. Ottawa, ON.

Olweus, D. (1991). Bully/victim problems among school children: Basic facts and effects of a school based intervention program. In D. J. Pepler \& K.H Rubin (Eds.), The development and treatment of childhood aggression (pp. 411-448). Hillsdale: Erlbaum.

Ortega, R., Elipe, P., Mora-Merchán, J. A., Calmaestra, J., \& Vega, E. (2009). The emotional impact on victims of traditional bullying and cyberbullying: A study of Spanish adolescents. Journal of Psychology, 217(4), 197-204. http://dx.doi.org/10.1027/0044-3409.217.4.197

Patchin, J. W., \& Hinduja, S. (2006). Bullies move beyond the schoolyard: A preliminary look at cyberbullying. Youth Violence and Juvenile Justice, 4(2), 148-169. http://dx.doi.org/10.1177/1541204006286288

Patchin, J. W., \& Hinduja, S. (2010). Cyberbullying and self-esteem. Journal of School Health, 80(12), 614-620. http://dx.doi.org/10.1111/j.1746-1561.2010.00548.x

Patchin, J. W., \& Hinduja, S. (2011). Traditional and nontraditional bullying among youth: A test of general strain theory. Youth \& Society, 43(2), 727-751. http://dx.doi.org/10.1177/0044118X10366951 
Patchin, J. W., \& Hinduja, S. (2012). Cyberbullying: An update and synthesis of research. In J. W. Patchin \& S. Hinduja (Eds.), Cyberbullying prevention and response: Expert perspectives (pp.13-35). New York: Routledge.

Raskauskas, J., \& Stoltz, A. (2007). Involvement in traditional and electronic bullying among adolescents. Developmental Psychology, 43(3), 564-575. http://dx.doi.org/10.1037/0012-1649.43.3.564

Rayner, C., \& Keashly, L. (2005). Bullying at work: A perspective from Britain and North America. In S. Fox \& P. Spector (Eds.), Counterproductive work behavior: Investigators of actors and targets (pp 271-296). Washington: American Psychological Association. http://dx.doi.org/10.1037/10893-001

Rodríguez-Muñoz, A., Moreno-Jiménez, B., Vergel, A., \& Hernández, E. (2010). Post-traumatic symptoms among victims of workplace bullying: Exploring gender differences and shattered assumptions. Journal of Applied Psychology, 40(10), 2616-2635. http://dx.doi.org/10.1111/j.1559-1816.2010.00673.x

Saldaña, J. (2009). The coding manual for qualitative research. Thousand Oaks: Sage.

Salin, D. (2003). Ways of explaining workplace bullying: A review of enabling, motivating, and precipitating structures and processes in the work environment. Human Relations, 56(10), 1213-1232. http://dx.doi.org/10.1177/00187267035610003

Sanders, J. (2009). Cyberbullies: Their motives, characteristics, and types of bullying. Paper presented at the XIV European Conference of Developmental Psychology (2009), Vilnius, Lithuania.

Schenk, A., \& Fremouw, W. (2012). Prevalence, psychological impact, and coping of cyberbully victims among college students. Journal of School Violence, 11(1), 21-37. http://dx.doi.org/10.1080/15388220.2011.630310

Schenk, A., Fremouw, W., \& Keelan, C. (2013). Characteristics of college cyberbullies. Computers in Human Behavior, 29(6), 2320-2327. http://dx.doi.org/10.1016〉j.chb.2013.05.013

Ševčíková, A., \& Šmahel, D. (2009). Online harassment and cyberbullying in the Czech Republic: Comparison across age groups. Zeitschrift für Psychologie/Journal of Psychology, 217(4), 227-229. http://dx.doi.org/10.1027/0044-3409.217.4.227

Shariff, S. (2008). Cyber-bullying: Issues and solutions for the school, the classroom and the home. Abingdon, UK: Routledge.

Shor, I. (1996). When students have power: Negotiating authority in a critical pedagogy. London: The University of Chicago Press

Simpson, R., \& Cohen, C. (2004). Dangerous work: The gendered nature of bullying in the context of higher education.Gender, Work, and Organization, 164-186. http://dx.doi.org/10.1111/j.1468-0432.2004.00227.x

Slonje, R., \& Smith, P. K. (2008). Cyberbullying: Another main type of bullying. Scandinavian Journal of Psychology, 49, 147-154. http://dx.doi.org/10.1111/j.1467-9450.2007.00611.x

Smith, A. (2007). Cyber-bullying affecting $17 \%$ of teachers, poll finds. The Guardian. Retrieved from http://www.guardian.co.uk/education/2007/jan/19/schools.uk

Smith, J., \& Yoon, J. (2013). Cyberbullying presence, extent, and forms in a midwestern post-secondary institution. Information Systems Education Journal, 11(3), 52. Retrieved from http://isedj.org/2013-11/N3/ISEDJv11n3p52.html

Smith, P. K. (2009). Cyberbullying: Abusive relationships in cyberspace. Zeitschrift für Psychologie/Journal of Psychology, 217(4), 180-181. http://dx.doi.org/10.1027/0044-3409.217.4.180

Smith, P. K. (2012). Cyberbullying and cyber aggression. In S. R. Jimerson, A. B. Nickerson, M. J. Mayer, \& M. J. Furlong (Eds.), Handbook of school violence and school safety: International research and practice (2nd ed., pp. 93-103). New York, NY: Routledge.

Smith, P. K., \& Slonje, R. (2010). Cyberbullying: The nature and extent of a new kind of bullying, in and out of school. In S.R. Jimerson, S.M. Swearer, \& D.L. Espelage (Eds.), Handbook of bullying in schools: An international perspective (pp. 249-262). New York, NY: Routledge.

Smith, P. K., Mahdavi, J., Carvalho, M., Fisher, S., Russell, S., \& Tippett, N. (2008). Cyberbullying: Its' nature and impact in secondary school pupils. Journal of Child Psychology \& Psychiatry, 49(4), 376-385. http://dx.doi.org/10.1111/j.1469-7610.2007.01846.x 
Smith, P., Mahdavi, J., Carvalho, M., \& Tippett, N. (2006). An investigation into cyberbullying, its forms, awareness and impact, and the relationship between age and gender in cyberbullying. (Brief No. RBX03-06) (RBX03-06). Retrieved from https://www.education.gov.uk/publications/eOrderingDownload/RBX03-06.pdf

Snakenborg, J., Van Acker, R., \& Gable, R. A. (2011). Cyberbullying: Prevention and intervention to protect our children and youth. Preventing School Failure: Alternative Education for Children and Youth, 55(2), 88-95. http://dx.doi.org/10.1080/1045988X.2011.539454

Spears, B., Slee, P., Owens, L., \& Johnson, B. (2009). Behind the scenes and screens: Insights into the human dimension of covert and cyberbullying. Journal of Psychology, 217(4), 189-196. http://dx.doi.org/10.1027.0044-3409.217.4.189

Strøm, I. F., Thoresen, S., Wentzel-Larsen, T., \& Dyb, G. (2013). Violence, bullying and academic achievement: A study of 15-year-old adolescents and their school environment. Child Abuse \& Neglect, 37(4), 243-251. http://dx.doi.org/10.1016/j.chiabu.2012.10.010

Suler, J. (2004). The online disinhibition effect. CyberPsychology \& Behavior, 7(3), 321-326. http://dx.doi.org/10.1089/1094931041291295

Tokunaga, R.S. (2010). Following you home from school: A critical review and synthesis of research on cyberbullying victimization. Computers in Human Behavior, 26, 277-287. http://dx.doi.org/10.1016/j.chb.2009.11.014

Twale, D., \& DeLuca, B. (2008). Faculty incivility: The rise of the academic bully culture and what to do about it. San Francisco: Jossey-Bass

Van Ameringen, M., Mancini, C., Patterson, B., \& Boyle, M. (2008). Post-traumatic stress disorder in Canada. CNS Neuroscience and Therapies, 14(3), 171-181. http://dx.doi.org/10.1111/j.1755-5949.2008.00049.x

Vance, J. W. (2010). Cyber-Harassment in Higher Education: Online Learning Environments. (Doctoral ), University of Southern California, Los Angeles, CA. Retrieved from http://digitallibrary.usc.edu/cdm/ref/collection/p15799coll127/id/309077

Vandebosch, H., \& Van Cleemput, K. (2009). Cyberbullying among youngsters: Profiles of bullies and victims. New Media \& Society, 11(8), 1349-1371. http://dx.doi.org/10.1177/1461444809341263

von Marées, N., \& Petermann, F. (2012). Cyberbullying: An increasing challenge for schools. School Psychology International, 33(5), 467-476. http://dx.doi.org/10.1177/0143034312445241

Walker, C. M., Sockman, B. J., \& Koehn, S. (2011). An exploratory study of cyberbullying with undergraduate university students. TechTrends, 55(2), 31-38. http://dx.doi.org/10.1007/s11528-011-0481-0

Wildermuth, S., \& Davis, C. B. (2012). Flaming the faculty: Exploring root causes, consequences, and potential remedies to the problem of instructor-focused uncivil online student discourse in higher education In L. Wankel \& C. Wankel (Eds.), Cutting edge technologies in higher education: Misbehavior online in higher education (Vol. 5, pp. 379-384 ). Binley, UK: Howard House. http://dx.doi.org/10.1108/S2044-9968(2012)0000005020

Willard, N. (2003). Off-campus, harmful online student speech. Journal of School Violence, 1(2), 65-93. Retreived from http://www.tandfonline.com.proxy.lib.sfu.ca/doi/pdf/10.1300/J202v02n01_04

Ybarra, M. L., \& Mitchell, K. J. (2004). Online aggressor/targets, aggressors, and targets: A comparison of associated youth characteristics. Journal of Child Psychology \& Psychiatry, 45(7), 1308-1316. http://dx.doi.org/10.1111/j.1469-7610.2004.00328.x

Ybarra, M. L., Diener-West, M., \& Leaf, P. J. (2007). Examining the overlap in internet harassment and school bullying: Implications for school intervention. Journal of Adolescent Health, 41, S45-S50. doi:10.1016/j.jadohealth.(2007).09.004

Yilmaz, H. (2011). Cyberbullying in Turkish middle schools: An exploratory study. School Psychology International. 32(6), 645-654. http://dx.doi.org/10.1177/0143034311410262

Zalaquett, C. P., \& Chatters, S. J. (2014). Cyberbullying in college: Frequency, characteristics, and practical implications. Sage Open, 4(1). http://dx.doi.org/10.1177/2158244014526721 